\title{
О защите высоковольтных мезаструктурных 4H-SiC-приборов от поверхностного пробоя: прямая фаска
}

\author{
(С) Н.М. Лебедева, Н.Д. Ильинская, П.А. Иванов \\ ${ }^{1}$ Физико-технический институт им. А.Ф. Иоффе Российской академии наук, \\ 194021 Санкт-Петербург, Россия \\ E-mail: Natali_lebedeva@mail.ioffe.ru
}

Поступила в Редакцию 2 октября 2019 г.

В окончательной редакции 15 октября 2019 г.

Принята к публикации 15 октября 2019 г.

Рассматриваются перспективы защиты высоковольтных $4 H$-SiC-приборов от краевого пробоя путем формирования мезаструктур с наклонными стенками, образующими прямую фаску. Проведено численное моделирование пространственного распределения электрического поля в высоковольтных $(\sim 1500 \mathrm{~B})$ обратносмещенных мезаэпитаксиальных $4 H-\mathrm{SiC} p^{+}-p-n_{0}-n^{+}$-диодах. Показано, что снятие прямой фаски под углами менее $10^{\circ}$ от плоскости $p-n_{0}$-перехода позволяет в несколько раз уменьшить краевое поверхностное поле по сравнению с полем в объеме. Для $4 H$-SiC-диодов с $p^{+}-n_{0}-n^{+}$-структурой, диодов Шоттки с $n_{o}$-базой, биполярных $n^{+}-p-n_{0}$-транзисторов предлагается комбинированный способ защиты - имплантация бора в периферийную область приборов в сочетании с формированием прямой фаски. Кратко рассматривается возможность изготовления мезаструктур с наклонными стенками с помощью фотолитографии и сухого травления карбида кремния.

Ключевые слова: карбид кремния, диод, прямая фаска, моделирование, сухое травление.

DOI: $10.21883 /$ FTP.2020.02.48904.9277

\section{1. Введение}

Карбид кремния политипа $4 H(4 H-\mathrm{SiC})$ благодаря своим уникальным электронным и тепловым свойствам является перспективным материалом для силовой электроники [1]. Ключевой проблемой при конструировании высоковольтных $4 H$-SiC-приборов является устранение нежелательных краевых и поверхностных эффектов. Например, в планарных 4H-SiC-диодах Шоттки силовые линии электрического поля сильно сгущаются у края шоттки-контакта, вызывая тем самым преждевременный краевой пробой в обратном направлении.

Для монополярных планарных $4 H-\mathrm{SiC}$-приборов с блокирующей $n_{0}$-базой - диодов Шоттки и МОПтранзисторов - было предложено множество конструктивно-технологических решений проблемы краевого пробоя, среди которых наибольшее распространение получили следующие: 1) формирование системы сильно легированных охранных $p^{+}$-колец (Guard Rings) c помощью локальной ионной имплантации алюминия или бора [2,3] и 2) формирование многозонной структуры JTE (Junction Termination Extension) [4,5], которая представляет собой несколько смыкающихся слаболегированных колец $p$-типа со строго фиксированной величиной поверхностной концентрации акцепторных примесей в каждом кольце (применяют ионную имплантацию алюминия, позволяющую точно дозировать поверхностную концентрацию акцепторов). Для охраны биполярных эпитаксиальных диодов с $p^{+}-n_{0}$-переходом хорошо себя зарекомендовали мезаструктурные охранные $p^{+}$-кольца [6], а также комбинированная структура меза-JTE [7], которая создается травлением мезы до $n_{0}$-слоя с последующим формированием JTE-колец с помощью ионной имплантации алюминия. Перечисленные технологии имеют свои специфические особенности и недостатки. В системах с охранными $p^{+}$-кольцами зазоры между ними должны быть очень узкими, порядка одного микрометра, что существенно усложняет фотолитографию при изготовлении приборов. Создание многозонных JTE-структур сопряжено с проведением прецизионного многоступенчатого процесса локального ионного легирования алюминием, предусматривающего высокотемпературные (до $2000^{\circ} \mathrm{C}$ ) отжиги для активации внедренных примемей. Кроме того, перечисленные способы не гарантируют, как правило, 100\%-й защиты от краевого пробоя. Поэтому разработки все более усовершенствованных методов защиты $4 H$-SiC-приборов от краевого пробоя продолжаются.

В настоящей работе рассматриваются перспективы защиты высоковольтных $4 H$-SiC-приборов от краевого пробоя путем формирования мезаструктур с наклонными стенками, образующими прямую фаску [8]. Проведено численное моделирование пространственного распределения электрического поля в обратносмещенной меза-диодной $p^{+}-p-n_{0}-n^{+}$-структуре с прямой фаской. Показано, что прямая фаска может быть эффективным конструктивным решением проблемы краевого пробоя за счет уменьшения поверхностного поля до величины намного меньшей поля в объеме. Для $4 H-\mathrm{SiC}$-приборов других типов - диодов с $p^{+}-n_{0}-n^{+}$-структурой, диодов Шоттки с $n_{0}$-базой, биполярных $n^{+}-p-n_{0}$-транзисторов - рассматривается комбинированный вариант защиты, предусматривающий имплантацию бора в периферийную область приборов 
в сочетании с формированием прямой фаски. Наконец, кратко обсуждается возможность изготовления мезаструктур с наклонными стенками с помощью фотолитографии и сухого травления карбида кремния.

\section{2. Формирование прямой фаски как способ уменьшения краевого поля в высоковольтных 4H-SiC-приборах}

Одним из первых способов снижения краевого поля в эпитаксиальных 4H-SiC-приборах было травление мезаструктур в расплаве щелочи. Позднее было разработано селективное сухое травление мезаструктур с вертикальными стенками [9]. В мезаструктурных диодах с вертикальными стенками электрическое поле на поверхности мезы удается понизить до величины поля в объеме, однако поверхностный пробой остается, как правило, доминирующим (из-за наличия на поверхности различного рода структурных неоднородностей, поверхностного заряда, загрязнений и т.п.). Вообще говоря, для мезаэпитаксиальных $4 H$-SiC-диодов вместо вертикальных стенок более эффективным могло бы стать формирование мезаструктур с наклонными стенками (по аналогии с формированием прямой или обратной фаски в кремниевых силовых приборах). На рис. 1 показаны два варианта конфигурации меза-диодных структур, изготовленных на подложке $n$-типа (отметим, что $4 H$-SiC-приборы изготавливаются исключительно на подложках $n$-типа). Для структур с резким асимметричным $p^{+}-n_{0}$-переходом лучше всего подошла бы обратная фаска (рис. 1, $a$; здесь поверхностное поле уменьшено по сравнению с объемным за счет расширения обедненной области перехода у поверхности $n_{0}$-слоя). Однако на практике реализовать

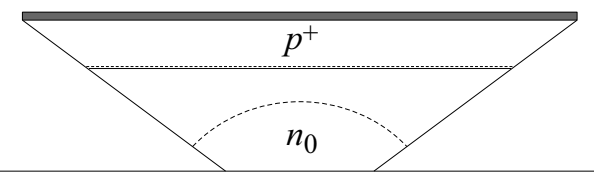

n-substrate

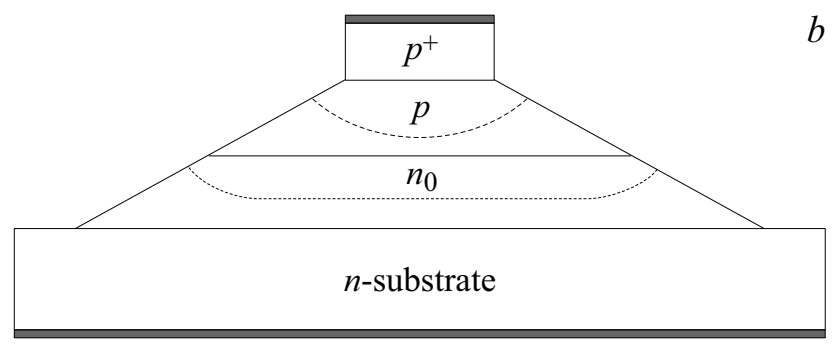

Рис. 1. Диодные структуры с обратной $(a)$ и прямой $(b)$ фасками. Пунктиром показаны границы обедненных областей блокирующих переходов.

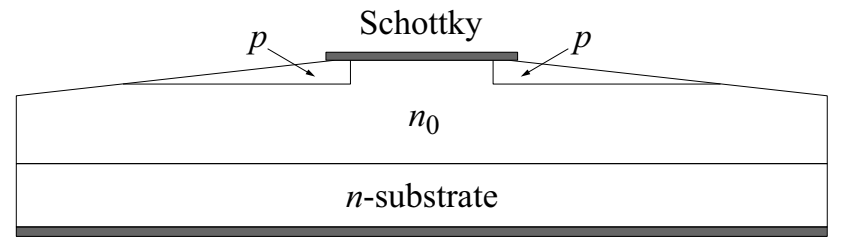

Ohmic

Рис. 2. Структура диода Шоттки с имплантированной $p$-областью и прямой фаской.

показанную на рис. 1, $а$ геометрическую конфигурацию не представляется возможным. Что касается прямой фаски, то ее применение может быть эффективным для таких приборов, в которых $p$-область блокирующего $p-n_{0}$-перехода умеренно легирована (рис. $1, b$; здесь за уменьшение поверхностного поля отвечает расширение обедненной области перехода у поверхности $p$-слоя). Такие $p-n_{0}$-переходы с концентрацией акцепторов в $p$-области $\sim 10^{17} \mathrm{~cm}^{-3}$ имеют, например, быстродействующие диодные размыкатели тока [10]. Вообще говоря, формирование прямой фаски может быть эффективным и для приборов других типов на основе $4 \mathrm{H}-\mathrm{SiC}$, в частности для диодов с $p^{+}-n_{0}-n^{+}$-структурой, шоттки-диодов с $n_{0}$-базой, биполярных $n^{+}-p-n_{0}$-транзисторов. Во всех случаях на периферии приборов вначале может быть создана умеренно легированная $p$-область (например, с помощью имплантации и радиационно-стимулированной диффузии бора в $n_{0}$-базу [11]; тем самым на крае прибора создается $p-n_{0}-n^{+}$-структура), а уже потом формируется прямая фаска (см. рис. 2, на котором для примера показана структура диода Шоттки с имплантированной p-областью и прямой фаской).

Для оценки эффективности прямой фаски мы провели численное моделирование пространственного распределения электрического поля в базовой обратносмещенной $p^{+}-p-n_{0}-n^{+}$-структуре. В следующем разделе подробно представлены объект, методика и результаты моделирования.

\section{3. Моделирование}

На рис. 3 показана аксиально симметричная модель мезаэпитаксиального $4 H$-SiC $p^{+}-p-n_{0}-n^{+}$-диода с прямой фаской. Задача нахождения пространственного распределения электрического поля $E(r, z)$ в обратносмещенном диоде решалась при следующих допущениях:

- легирующие примеси - доноры и акцепторы однородно распределены в пределах $n$ - и $p$-областей соответственно;

- доноры и акцепторы полностью ионизированы;

- поверхностный заряд на боковой стенке диодной структуры равен нулю;

- внешная граница $p^{+}$-области находится под нулевым потенциалом; 


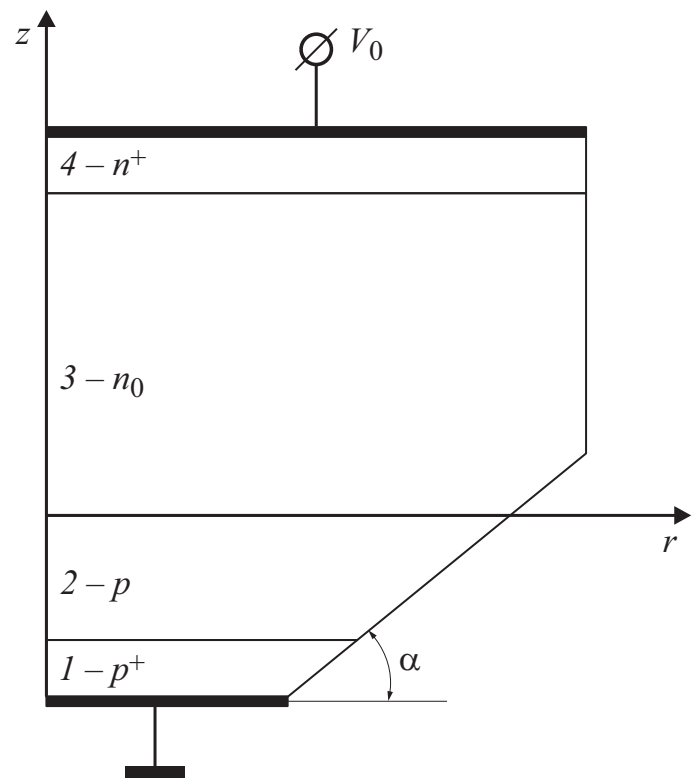

Pис. 3. Структура моделируемого мезаэпитаксиального $4 H-\mathrm{SiC} p^{+}-p-n_{0}-n^{+}$-диода с прямой фаской.

- внешняя граница $n^{+}$-области находится под положительным потенциалом $V_{0}$;

- обратный ток через диод равен нулю;

- концентрации электронов в $p^{+-}$и $p$-областях и дырок в $n^{+}$- и $n$-областях равны нулю;

- концентрации дырок $\left(p_{i}\right)$ в $p^{+}$и $p$-областях и электронов $\left(n_{j}\right)$ в $n^{+}$и $n_{0}$-областях определяются, в соответствии со статистикой Больцмана, локальной величиной электрического потенциала $V(r, z)$ :

$$
\begin{gathered}
p_{i}=N_{A i} \exp \left(-\frac{q V}{k T}\right) ; i=1,2, \\
n_{j}=n_{D j} \exp \left[-\frac{q\left(V_{0}-V\right)}{k T}\right] ; j=3,4,
\end{gathered}
$$

где $q$ - элементарный (положительный) заряд, $N_{A i}$ и $N_{D i}$ - концентрации акцепторов и доноров, $k T-$ тепловая энергия.

C учетом принятых допущений задача нахождения $E(r, z)$ сводится к решению уравнения Пуассона в диэлектрике, локальная плотность объемного заряда в котором зависит от потенциала $V(r, z)$ :

- плотность отрицательного объемного заряда в $p^{+}$- и р-областях

$$
\rho_{p i}=-q\left(N_{A i}-p_{i}\right),
$$

- плотность положительного объемного заряда в $n^{+}$- и n-областях

$$
\rho_{n j}=q\left(N_{D j}-n_{j}\right) .
$$

В расчетах параметры эпитаксиальной структуры диода выбирались такими, чтобы напряжение пробоя идеального одномерного диода составляло $\sim 1.5$ кВ. Концентрации акцепторов в $p^{+}$- и $p$-областях: $N_{A 1}=5 \cdot 10^{18} \mathrm{~cm}^{-3}$ и $N_{A 2}=8 \cdot 10^{16} \mathrm{~cm}^{-3}$; концентрации доноров в $n_{0^{-}}$и $n^{+}$-областях: $N_{D 3}=8 \cdot 10^{15} \mathrm{~cm}^{-3}$ и $N_{D 4}=5 \cdot 10^{18} \mathrm{~cm}^{-3}$. Толщины $p^{+}, p-, n_{0^{-}}$и $n^{+}$-слоев: 1 , 2,7 и 1 мкм соответственно. Потенциал $V_{0}$ принимался равным $1200 \mathrm{~B}$, угол фаски $\alpha$ варьировался в пределах от 3 до $11^{\circ}$. Расчеты проводились с помощью компьютерной программы, реализующей численное моделирование двумерных электростатических полей методом конечных элементов.

На рис. 4 для примера показано рассчитанное двумерное распределение электрического поля в структуре с фаской, снятой под углом $\alpha=5.7^{0}$. Как видно, в объеме диода (при радиусах $r$ в пределах от 0 до 20 мкм) поле имеет квазиодномерный характер распределения. Здесь максимальная величина поля (в плоскости $p-n_{0}$-перехода) составляет $2 \cdot 10^{6} \mathrm{~B} / \mathrm{cm}$; область пространственного заряда (ОПЗ) проникает в $n_{0}$-слой на всю его толщину 7 мкм, а в $p$-слой — на глубину $\sim 1$ мкм. При радиусах $r$ более 25 мкм поле приобретает двумерный характер распределения, которое характеризуется следующими особенностями:

- за пределы квазиодномерной области ОПЗ расширяется (в латеральном направлении) на расстояние $\sim 30$ мкм; отметим, что на этом расстоянии плоскость $p-n_{0}$-перехода уже выходит на поверхность фаски;

- пик поля смещен по нормали от поверхности фаски (оставаясь в плоскости $p-n_{0}$-перехода) на расстояние $\sim 1.5$ мкм;

- пиковое поле немного превышает максимальную величину поля в квазиодномерной части диода; в месте выхода плоскости $p-n_{0}$-перехода на поверхность фаски поле практически обращается в нуль (рис. 5);

- максимальное поле на поверхности фаски меньше пикового поля в 2.6 раза (рис. 6).

На рис. 7 показана зависимость максимального поля на поверхности фаски от угла $\alpha$. Как видно, поле мо-

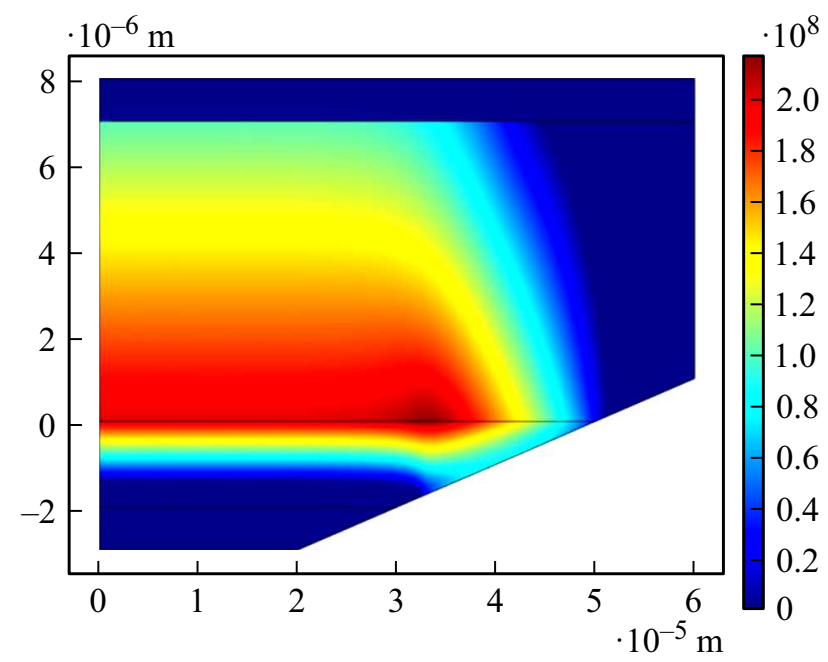

Рис. 4. Двумерное распределение электрического поля $\left(\alpha=5.7^{\circ}\right)$. 


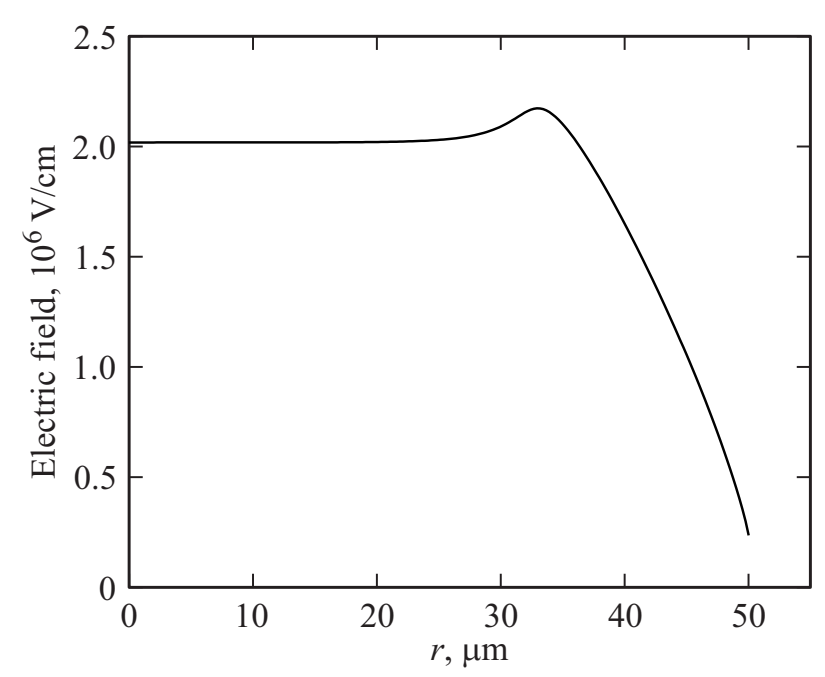

Рис. 5. Зависимость электрического поля в плоскости $p-n_{0}$-перехода $(z=0)$ от координаты $r\left(\alpha=5.7^{\circ}\right)$.

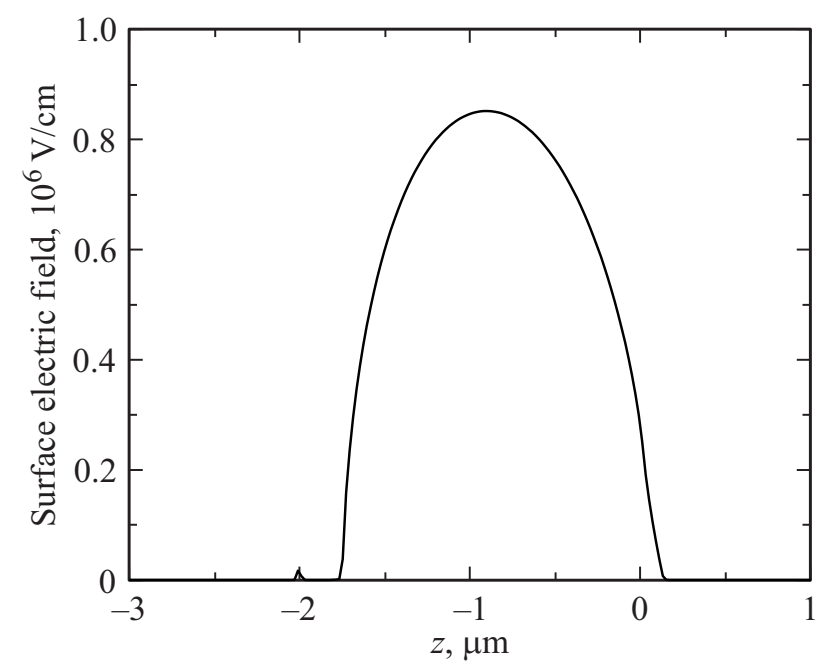

Рис. 6. Зависимость электрического поля на поверхности фаски от координаты $z\left(\alpha=5.7^{\circ}\right)$.

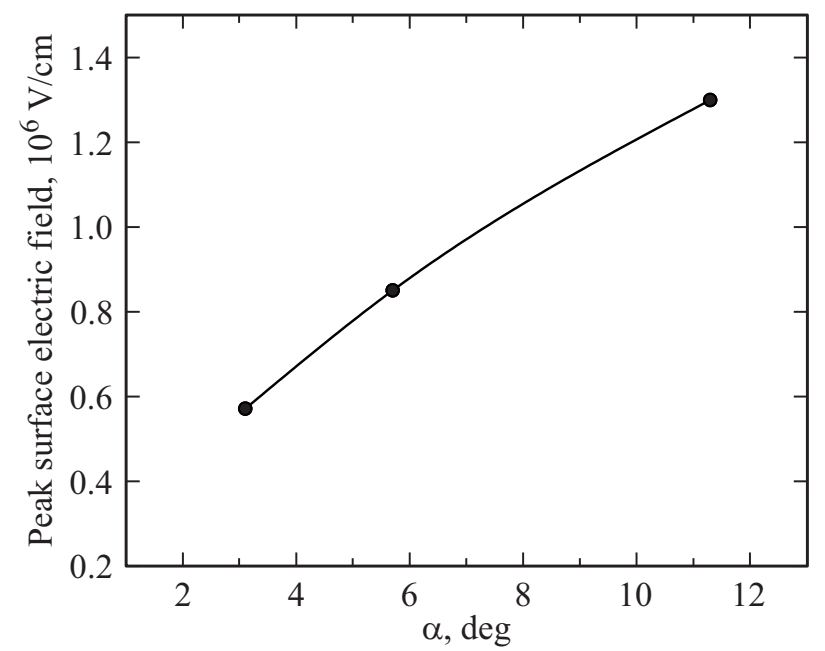

Рис. 7. Зависимость максимального электрического поля на поверхности фаски от угла $\alpha$. нотонно уменьшается при уменьшении $\alpha$. Фаска, снятая под углом около $3^{\circ}$, позволяет снизить максимальную величину поверхностного поля по сравнению с полем в объеме в 4 раза.

Таким образом, результаты моделирования показывают, что для мезаэпитаксиальных $4 H-\mathrm{SiC} p^{+}-p-n_{0}-n^{+}$диодов прямая фаска может быть эффективным конструктивным решением проблемы краевого пробоя за счет уменьшения поверхностного поля до величины, намного меньшей поля в объеме.

Далее кратко рассматриваются технологические аспекты изготовления мезаструктур с наклонными стенками с помощью сухого травления карбида кремния.

\section{4. О технологических возможностях формирования прямой фаски}

В кремниевой технологии фаску снимают с помощью механической шлифовки: торец приборов круглой формы (диаметром не менее 2-3 см) обрабатывают на шар-шлифе. В случае карбида кремния такой способ исключен, так как изготавливаемые по групповой технологии чипы имеют, во-первых, прямоугольную форму, а во-вторых, они имеют малые размеры (поперечные размеры чипов составляют обычно до 3-5 мм, не более). В принципе прямая фаска может быть создана с использованием фотолитографических методов и процессов сухого травления карбида кремния. Для того чтобы стенки при травлении получались наклонными (с малым углом $\alpha)$, необходим такой процесс, при котором маска и карбид кремния травятся примерно с одинаковой скоростью (селективность травления $1: 1$ ). Кроме того, край маски по форме должен повторять будущий профиль прямой фаски. В этом случае краевой профиль маски будет „копироваться“ в карбиде кремния (очевидно, что имеющиеся технологические возможности создания маски с „острым“ краем будут ограничивать снизу величину угла $\alpha$ ). Наиболее технологичная маска это маска из фоторезиста, а наиболее подходящий способ травления карбида кремния, обеспечивающий селективность 1:1 по отношению к фоторезисту, - это ионно-лучевое травление (ИЛТ) пучком ионов аргона. Метод ИЛТ (прямое физическое распыление) характеризуется относительно малыми скоростями травления, поэтому обычно не используется для травления на большие глубины. В случае мезаструктурных $4 H$-SiCприборов с вертикальными стенками для выравнивания краевого и объемного полей мезаструктуру необходимо травить до подложки на всю толщину блокирующего $n_{0}$-слоя (на глубину $\sim 10$ мкм). Как показало моделирование, при формировании прямой фаски в $4 H-\mathrm{SiC}$ приборах с $p-n_{0}$-переходом нет необходимости вытравливать мезаструктуру до $n$-подложки: достаточно протравить ее до плоскости $p-n_{0}$-перехода (на глубину $\sim 1.5-2$ мкм). 


\section{5. Заключение}

В будущем мы планируем разработать групповую технологию формирования мезаструктур с наклонными стенками и изготовить экспериментальные высоковольтные ( $1500 \mathrm{~B}) 4 H-\mathrm{SiC} p^{+}-p-n_{0}-n^{+}$-диоды с прямой фаской. Для изготовления диодов планируется использовать имеющиеся коммерческие $4 H$-SiC-пластины с теми же параметрами эпитаксиальной структуры (толщины слоев, тип их проводимости и уровень легирования), которые были приняты при моделировании. Изготовленные диоды должны быть исследованы на предмет устойчивости их работы в режиме лавинного пробоя.

\section{Конфликт интересов}

Авторы заявляют, что у них нет конфликта интересов.

\section{Список литературы}

[1] T. Kimoto, J.A. Cooper. Fundamentals of silicon carbide technology: growth, characterization, devices, and applications (Wiley-IEEE Press, 1 edn, 2014).

[2] D.C. Sheridan, G. Niu, J.N. Merrett, J.D. Cressler, C. Ellis, C.-C. Tin. Sol. St. Electron., 44, 1367 (2000).

[3] П.А. Иванов, И.В. Грехов, Н.Д. Ильинская, Т.П. Самсонова. ФТП, 43, 527 (2009).

[4] D.C. Sheridan, G. Niu, J.D. Cressler. Sol. St. Electron., 45, 1659 (2001).

[5] P. Alexandrov, J.H. Zhao, W. Wright, M. Pan, M. Weiner. Electron. Lett., 37, 1139 (2001).

[6] П.А. Иванов, И.В. Грехов, Н.Д. Ильинская, Т.П. Самсонова, А.С. Потапов. ФТП, 39, 1475 (2005)

[7] X. Deng, H. Xiao, J. Wu, H. Shen, C. Li, Y. Tang, Y. Zhang, B. Zhang. Superlat. Microstruct., 88, 167 (2015).

[8] Ю.А. Евсеев, П.Г. Дерменжи. Силовые полупроводниковые приборы (М., Энергоатомиздат, 1981).

[9] А.Л. Сыркин, И.В. Попов, В.Е. Челноков. Письма ЖТФ, 12, 240 (1986).

[10] П.А. Иванов, О.И. Коньков, Т.П. Самсонова, А.С. Потапов. Письма ЖТФ, 44, 3 (2018).

[11] И.В. Грехов, П.А. Иванов, Н.Д. Ильинская, О.И. Коньков, А.С. Потапов, Т.П. Самсонова. ФТП, 42, 211 (2008).

Редактор А.Н. Смирнов

\section{Edge termination technique for high-voltage mesa-structure 4H-SiC-devices: negative beveling}

\author{
N.M. Lebedeva, N.D. Il'inskaya, P.A. Ivanov \\ loffe Institute, \\ 194021 St. Petersburg, Russia
}

Abstract For high-voltage $4 \mathrm{H}$-SiC-devices, formation of mesastructures with inclined walls (negative beveling) is considered as a method of edge termination technique. Numerical simulation of spatial distribution of the electric field in high-voltage $(\sim 1500 \mathrm{~V})$, reverse biased $4 H$-SiC mesa-epitaxial $p^{+}-p-n_{0}-n^{+}$-diodes has been performed. It is shown that negative beveling with small angles (less than 10 degres from the platelet surface) should help to reduce the edge electric field several times as compared to the bulk one. Local boron implantation combined with negative beveking is suggested as the edge termination technique for $p^{+}-n_{0}-n^{+}$-diodes, Schottky diodes with $n_{0}$-blocking base and bipolar junction $n^{+}-p-n_{0}$-transistors. The method of making mesa-structures with inclined walls via photolithograhy and dry etching is briefly discussed. 